\title{
Killing of animals in science - is it always inevitable?
}

\section{Nuno H Franco}

Originally published in Food futures: ethics, science and culture. I. Anna S. Olsson, Sofia M. Araújo and M. Fátima Vieira, Editors. 2016, Wageningen Academic Publishers: Wageningen.

\begin{abstract}
Within the ethical discussion of animal experimentation, the questions of why, how many, and under what circumstances animals are (or should be) used takes precedence over the fact that virtually all lab animals are killed after their scientific utility. When death is indeed an issue, the discussion often concerns the circumstances of death, from a welfare pointof view. This is a likely consequence of two factors: firstly, killing being seen as an inevitable consequence of animal use and, second, a predominantly "welfarist-utilitarian" influence in the ethical and legal framework on the acceptability of animal research. While the former leads to the killing of lab animals being implicitly accepted along with the acceptance of animal research itself, the latter makes death a lesser issue (provided it is carried out humanely), as "being dead" is not in itself seen as a welfare problem, and the early euthanasia of animal models of disease can moreover prevent avoidable suffering (i.e. by humane end-points). In this landscape, animal experimentation without the burden of killing animals seems unfeasible, if not undesirable. However, while acknowledging that most studies do require killing animals out of scientific (e.g. from the need to extract largeenough samples from small animals) or ethical (when animals would otherwise suffer needlessly) necessity, it remains to be ascertained whether a) this is true for all cases or b) that curtailing the life of laboratory animals is of little ethical importance. Accepting that at least some - animal research is relevant, ethically acceptable and presently not replaceable, it should nevertheless be reflected upon whether there can be a scientific, ethical and legal framework within which a "no-kill" approach may be equated, for some cases. A few examples are herein presented to discuss current possibilities and constraints, and help identify under which circumstances can a new set of "3Rs" - Re-use, Rehabilitation and Rehoming - be applied as an alternative to the killing of animals when their scientific usefulness ends.
\end{abstract}

Note: This topic is further discussed in Franco \& Olsson (2016). "Killing animals as a necessary evil? The case of animal research." The end of animal life: a start for ethical debate. Wageningen. The present text introduces a new set of 3 Rs for avoiding killing animals in research, and results from an ongoing survey. our publications, please visit http://repositorio-aberto.up.pt/ 


\section{Killing laboratory animals as a moral issue}

Animals used in scientific procedures are typically euthanized, when the experiment ends. In the EU 11.5 million vertebrates (European Commission 2013) are killed annually for research. This corresponds however to just 2.3 vertebrates - mostly rodents and fish - per 100 EU citizens per year (for a population of 502.5 million EU citizens, Eurostat 2012) for all basic and applied biomedical science in academia and industry, a figure that gets dwarfed in comparison with the number of animals - mostly cows, pig, sheep, poultry and fish killed for food in the EU daily (for statistics see Eurostat 2008; Eurostat 2009; Eurostat 2011). Considering that only between 1-9\% (0.3\% in Portugal, Centro Vegetariano 2008) of people in western countries are vegetarians, we can assume most people, even if concerned about animal welfare, do not oppose, in principle the killing of animals for food, despite more replacement alternatives might be available for this purpose than for biomedical research. Nonetheless, not only is an ad populum argument hardly acceptable, it should also be pointed out that while meat production without killing is for the time being inconceivable - albeit eventually achievable through in-vitro meat culture (Weele 2014) - biomedical experiments may not necessarily require curtailing animal lives. Furthermore, regardless of number, we have moral obligations towards all animals under our care and responsibility.

Following Jeremy Bentham - who laid the foundations of utilitarian moral philosophy and for whom animal research was acceptable, provided it had "a determinate object, beneficial to mankind" (Boralevi 1984) - acceptability of animal research is currently based on a predominantly utilitarian evaluation between the harm endured by animals and the potential scientific and medical benefits of the experiments. For this reason, greater attention is given to preventing or minimizing animal suffering than to avoid killing, insomuch as to the killing of lab animals not being accounted as a procedure if no other interventions are carried out, in current EU legislation (European Commission 2010). Indeed, animals killed by routine culling are not even accounted for statistical purposes. This landscape reflects a predominantly welfarist view of what constitutes good practice, by which painless killing of laboratory animals poses no ethical problems, as nonexistence implies absence of negative experiences.

In the tenet of the Three Rs (Russell and Burch 1959) the value of animal life is patent in the principle of 'replacement', but probably even more so in the principle of 'reduction', as using - and ultimately killing - as few animals as possible is valued as the most ethical approach, when replacement is unfeasible. In this sense, 'reduction' alludes to the "badness of killing" argument (Hansen, Sandøe et al. 1999), by which one would as far as possible avoid taking the lives of animals. However, whenever 'reduction' might conflict with 'refinement' - e.g. anytime reducing the number of animals used would result in a higher burden for each individual animal (Olsson, Franco et al. 2012; Franco and Olsson 2014) - the latter is widely viewed as the priority, in line with a "fairness to the individual" position (Tannenbaum 1999), as well as animal research regulations in most countries.

In a hypothetical, but realistic, 'reduction'/'refinement' dilemma presented to researchers undergoing mandatory training to work with animals, in a survey carried out in eight European cities (Franco et al, submitted) (Figure 1), 70\% of respondents would favour pair 
housing, thus using and killing more animals, to avoid the distress associated with single housing.

Mice are social animals, to which individual housing is stressful. However, in a given experiment, each cage must be considered as a single experimental unit due to "cageeffects", regardless of the number of animals in each cage.

Having no financial or logistic constraints, which of the following approaches would you take, if 20 experimental units are needed?

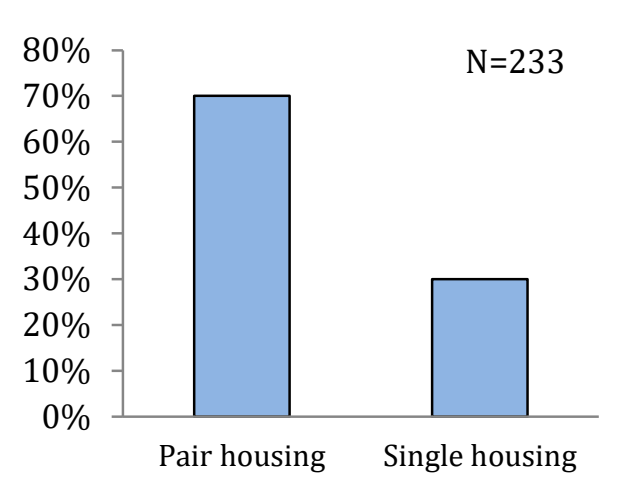

Figure 1.. A reduction/refinement dilemma presented to laboratory animal science course participants.

However, for a more extreme hypothetical case-study (Franco and Olsson 2014), where a painful procedure that could either be carried out twenty times in one mouse or just once in twenty mice, scientists were much more divided, with only 53\% favouring using more animals. Also, if subjects were companion species or primates the preferred option would be using a single animal. This suggests that, for scientists, the perceived value of animal life will depend on the context and the species in question.

Killing might also pose an animal welfare issue that goes beyond the circumstances of death, as it is in the interest of the animal to not only avoid negative feelings but also experience positive ones. Hence,

death deprives an animal of the positive feelings it would otherwise experience in its lifetime, provided it would be a life worth living (Yeates 2010) This is relevant given the considerable proportion of procedures with little to no welfare impact, in which animals that could make a full recovery and live healthy lives afterwards are nonetheless euthanized at a young age.

For those who follow a stricto sensu animal rights perspective - i.e. following Tom Regan (1989) - no deliberate killing of animals for the sake of human interests is acceptable. In fact, even if animals are allowed the 'right to live, an animal rights advocate will not accept animal research on the grounds that I makes animals 'means to an end'. As for a preference utilitarian, hardly any animal research is acceptable (Singer, 2006), as direct benefits from any single experiment that could offset the cost endured by animals in that experiment are seldom observed, while killing laboratory animals goes against their interest in keeping on living. However, the case could be made that a preference utilitarian should accept an animal experiment - even if medical benefits are not directly reaped whenever the benefits for animals (such as 'freedom' from hunger, thirst, cold, predators, 
or disease) can outweigh the costs (such as captivity or transient, mild harm), and animals are allowed to live a long, healthy life. Indeed, if most people would not accept reduction and replacement as legitimate goals for the keeping of companion animals, or even farm animals (when these are expected to have good quality of life. Olsson et al 2012), why should laboratory animals not be allowed to live a life worth living when this is possible both during and after their scientific use?

\section{Re-use, Rehabilitate, Rehome: An alternative to killing laboratory animals}

Animals used in research are typically killed for three reasons: a) as a scientific requirement; b) to prevent avoidable suffering or c) for financial, logistic, technical or even cultural reasons, secondary to the scientific process.

Euthanizing animals to spare them from suffering (i.e. humane end-points, not only considered best practice but also a legal requirement, Morton 1999) provides a morally compelling justification for killing. However, killing out of scientific necessity might be avoided by changing methodological approaches. For example, post-mortem evaluation can sometimes be replaced by imaging technologies that allow monitoring disease progress in the living animal - e.g. tuberculosis infections (e.g. Andreu, Elkington et al. 2012), hence avoiding killing animals for this purpose. Methodological adaptations to prevent killing animals are not available for most cases, but there is a wider margin for preventing it from happening due to secondary reasons. One such reason is the predominance of single-sex studies, i.e. using either females - e.g. to avoid aggressionrelated problems with group-housed males (Van Loo, Van Zutphen et al. 2003) - or (more often) males (Wald and Wu 2010), which leads to the culling of animals of the other sex. There are usually no reasons for not using both male and female animals, which moreover allows detecting possible sex differences (insomuch as now being a requirement for all $\mathrm{NIH}$-funded research, Clayton and Collins 2014).. Routine culling may also result from scientists not planning experiments in advance, which makes animal facilities and commercial breeders breed in excess to be able to supply them on very short notice (Hawkins, Morton et al. 2004).

One possible alternative for killing laboratory animals is their continuous use (such as in pharmacokinetic studies) or re-use in other experiments, provided it does not have a detrimental effect in their wellbeing. For example, when large volume samples are needed, animals of smaller species - like rodents or fish - usually have to be euthanized for sample collection, with the number of animals needed (and killed) being multiplied when samples must be collected at different time-points. When using larger animal species, however, repeated sampling can be carried out without having to kill different animals at several time points, with the advantage of eliminating inter-individual variability, since each animal can be its own control (e.g. Dell, Holleran et al. 2002). And while repeated sampling has less impact for larger species, rodents can for instance be re-used in single-dose pharmacokinetic studies of non-toxic substances, with no significant impact on their welfare (Balani et al 2008). 
Laboratory rodents and fish have relatively short life-spans, but larger animal species, such as dogs, may live much longer lives, which with adequate care can be healthy and worth living lives, even in laboratories (Franco et al 2014). But what to do when their scientific utility has for any reason reached its end? One option is their re-homing as companion animals or to sanctuaries (Wolfensohn 2010), which must be preceded by their rehabilitation, i.e. adapting them to a life a completely different environment, with different people and different routines. Indeed, in most cases re-use, rehabilitate and rehoming here proposed as a set of "three Rs" for preventing the killing of animals in research must necessarily go together, and in this order, as it might be financially and logistically unfeasible to rehabilitate and rehome animals that do not provide an extended scientific usefulness. Rehoming is still far from being common practice, except for the retirement of chimpanzees to sanctuaries in the USA, where a fund has been established for this purpose, since euthanasia of surplus chimpanzees under the care of federal public agencies is forbidden. It might be more difficult to envisage purpose-bred laboratory animals outside their scientific role - and hence to consider them appropriate for a life outside the laboratory (Kerwin 2006) - but there are several examples of successful programs for re-homing of laboratory cats and dogs into family homes and non-human primates into sanctuaries (e.g. Carbone 1997; LASA 2004; DiGangi, Crawford et al. 2006; Wolfensohn 2010), showing it can be a feasible option.

In order to make rehabilitation and re-homing of lab animals a feasible option, it must be contemplated in laws and regulations. One example is the German 'Animal Welfare Act' Tierschutzgeset - by which the killing of any vertebrate without a 'sound reason' is forbidden. Although animal research - and many other uses - is deemed a 'sound reason' by the Tierschutzgeset, it has served as a legal framework in Germany for rehoming laboratory animals after their use in scientific research (Doehring and Erhard 2005). The rehabilitation and re-homing of non-human primates, cats, and dogs used in research is also encouraged (although not required) in present EU legislation (European Commission 2010). A more explicit legal framework to allow rehabilitation of laboratory animals is patent in the 2006 amendment of the Indian law regulating animal experiments, which makes researchers using large animals responsible for what happens to them afterwards (de Boo and Hendriksen 2005; Pereira and Tettamanti 2005). Thus, researchers using dogs, cats, sheep, goats, cattle, horses, non-human primates or other large animal species must include in the research budget expenses related to their aftercare and rehabilitation (unless euthanasia is deemed necessary). Rehabilitation of small laboratory mammals is however "not necessary", but is open to consideration by institutional animal ethics committees.

Even for smaller species, such as rodents, rehabilitation and rehoming may in some circumstances be feasible, and sometimes even easier than for larger animals, as rodents are easy and affordable to maintain. Their short life-span also makes them less demanding in terms of the commitment from potential adopters. Also, it might be easier for rodents kept enclosed with their social group to adapt to a new environment than for a dog that has to adapt from living primarily with other dogs to be the single canine member of a human family. One interesting option for rodents is their use as classroom

INSTITUTO DE INVESTİGAÇÃO E INOVAÇÃO EM SAÚDE UNIVERSIDADE DO PORTO

Rua Alfredo Allen, 208 4200-135 Porto Portugal +351220408800 
pets in schools (Baumans, Coke et al. 2007). Rodents can be housed in classrooms in highly enriched habitats, and used as an educational resource, including for teaching respect for animals or to deal with loss (Huddart and Naherniak 2005; Fonseca, Franco et al. 2011). In any case, regardless of animals being adopted by families or schools, it is central that adopters are able and capable of caring for them for as long as they live. The rehabilitation of laboratory animals might raise considerable difficulties. Firstly, it might be labour demanding, costly and time consuming. Also, it is difficult to ensure re-homed animals will be housed and taken care of under at least the same standards found in animal facilities; as well as to define what to do in case animals are found to be mistreated outside. Animals might also manifest physical and behavioural abnormalities from prolonged captivity or inadaptation to re-homing conditions (Tettamanti, Veeraraghavan et al.; Hubrecht 2002).

If animal research is portrayed to the public as only being carried out when no alternatives are available, it follows that the same should be applied for killing. However, for the above reasons, avoiding killing might be unfeasible, and humane euthanasia might often be the only available or ethically referable option. However, the goals of re-use, rehabilitation and re-homing deserves more serious thought, whenever these can allow laboratory animals to live healthy, longer, and worth living lives, either within laboratories, or outside them.

\section{REFERENCES}

Andreu, N., Elkington, P. T. and Wiles, S. (2012) Molecular Imaging in TB: From the Bench to the Clinic. In P.-J. Cardona (eds.), Understanding Tuberculosis - Global Experiences and Innovative Approaches to the Diagnosis. InTech.

Balani, S.K., Lu, C., Cardoza, K., Berg, C., Zhang, J. and Lee, F.W. (2008) Proposed New Addition to 3Rs for Ethical and Humane Use of Rats in Pharmacokinetic Studies-'Recycle'. Drug metabolism letters 2(3): 193-197.

Baumans, V., Coke C., Green J., Moreau E., Morton D., Patterson-Kane, E., Reinhardt, A., Reinhardt V., Van Loo, P. (2007) Making Life Easier for Animals in Research Labs. Washington, Animal Welfare Institute.

Boralevi, L. C. (1984) Bentham and the Oppressed, W. de Gruyter.

Broadhead, C. L., G. Betton, et al. (2000) Prospects for reducing and refining the use of dogs in the regulatory toxicity testing of pharmaceuticals. Human \& Experimental Toxicology 19(8): 440-447.

Carbone, L. (1997) Adoption of Research Animals. Animal Welfare Information Center Newsletter 7.

Centro Vegetariano (2008) Portugal: 30000 Vegetarianos.

http://www.centrovegetariano.org/Article-451-Portugal\%253A\%2B30\%2B000\%2BVegetarianos.html (last accessed in May 2016)

Clayton, J. A. and Collins F.S. (2014) NIH to balance sex in cell and animal studies. Nature 509(7500): 282-283.

de Boo, J. and Hendriksen C.F.M. (2005) Reduction strategies in animal research: a review of scientific approaches at the intra-experimental, supra-experimental and extra-experimental levels. ATLAAlternatives to Laboratory Animals 33(4): 369-377. 
Dell, R. B., Holleran s. and Ramakrishnan, R. (2002) Sample size determination. ILAR Journal 43(4): 207213.

DiGangi, B. A., Crawford, P.C and Levy, J.K. (2006) Outcome of Cats Adopted From a Biomedical Research Program. Journal of Applied Animal Welfare Science 9(2): 143-163.

Doehring, D. and Erhard M.H. (2005) [Whereabouts of surplus and surviving laboratory animals] ALTEX 22(1): 7-11

European Commission (2010) Directive 2010/63/EU of the European Parliament and of the Council of 22 September 2010 on the protection of animals used for scientific purposes. E. Commission. Brussels, Official Journal of the European Union. L276: 33-79.

European Commission (2013) Seventh Report on the Statistics on the Number of Animals used for Experimental and other Scientific Purposes in the Member States of the European Union. Brussels.

Eurostat (2008) Poultry statistics in the European Union: flock numbers, hatcheries, trade and slaughterings. Data in focus 31/2008.

Eurostat (2009) EU cattle, pigs, sheep and goats: monthly slaughter statistics in 2008. Data in focus $15 / 2009$

Eurostat (2011) Fishery Statistics. Agriculture and fishery statistics - Main results 2010-11. Luxembourg. Publications Office of the European Union.

Eurostat (2012) Europe in Figures - Eurostat yearbook 2012. Luxembourg, Publications Office of the European Union: 119.

Fonseca, M J., Franco, N.H., Brosseron, F., Tavares, F., Olsson, I.A.S., and Borlido-Santos, J. (2011) Children's attitudes towards animals: evidence from the RODENTIA project. Journal of Biological Education 45(3): 121-128

Franco, NH, Magalhẽs-Sant'Ana, M, Olsson, IAS. (2014) Welfare and Quantity of Life. Dilemmas in Animal Welfare, 46-66.

Franco, N.H. and Olsson I.A.S. (2014) Scientists and the 3Rs: attitudes to animal use in biomedical research and the effect of mandatory training in laboratory animal science. Laboratory animals 48(1): $50-60$.

Hansen, AK, P. Sandøe, Svendsen, O., Forsman, B. and Thomson, P. (1999) The need to refine the notion of reduction. Humane endpoints in animal experiments for biomedical research. C. Hendriksen and D. Morton. London, RSM Press: 139-144.

Hawkins, P., Morton, D.B., Bevan, R., Heath, K., Kirkwood, J., Pearce, P., Scott, L., Whelan, G. and Webb, A. (2004) Husbandry refinements for rats, mice, dogs and non-human primates used in telemetry procedures. Seventh report of the BVAAWF/FRAME/RSPCA/UFAW Joint Working Group on Refinement, Part B. Lab Anim 38(1): 1-10.

Hubrecht, R. (2002) Comfortable quarters for laboratory dogs in research institutions. Comfortable quarters for laboratory animals. V. Reinhardt and A. Reinhardt, Animal Welfare Institute. 56-64.

Huddart, S. and Naherniak C. (2005) Animals in the Classroom. Teaching Green: The Elementary Years : Hands-on Learning in Grades K-5. T. Grant and G. Littlejohn. Toronto, New Society Publishers: 101107.

Kerwin, A.M. (2006) Overcoming the Barriers to the Retirement of Old and New World Monkeys From Research Facilities. Journal of Applied Animal Welfare Science 9(4): 337-347. 
LASA (2004) LASA Guidance on the Rehoming of Laboratory Dogs. A report based on a LASA working party and LASA meeting on rehoming laboratory animals. M. Jennings and B. Howard.

Morton, D.B. (1999) Humane endpoints in animal experimentation for biomedical research. Humane endpoints in animals experiments for biomedical research. C. F. M. Hendriksen and D. B. Morton. London, Royal Society of Medicine Press: 5-12.

Olsson, I.A.S., Franco, N.H., Weary, D.M. and Sandøe, P. (2012) The 3Rs Principle-Mind the Ethical Gap! ALTEX (2011): 333-336.

Pereira, S. and Tettamanti M.(2005) Ahimsa and alternatives - The concept of the 4 th R. The CPCSEA in India. $A L T E X$ 22(1): 3-6.

Regan, T. (1989) The case for Animal Rights. Animal Rights and Human Obligations - Second Edition. T. Regan and P. Singer. New jersey, Prentice Hall.

Russell, W.M.S. and Burch R.L. (1959) The principles of humane experimental technique London, Methuen \& Co. Ltd.

Singer, P. Singer, P. (2006) Setting Limits on Animal Testing. The Sunday Times. December 3, 2006.

Stephens, M. L., Conlee, K., Alvino, G. and, Rowan, A.N. (2002) Possibilities for refinement and reduction: future improvements within regulatory testing. ILAR Journal 43 Suppl: S74-79.

Tannenbaum, J. (1999) Ethics and pain research in animals. ILAR Journal 40(3): 97-110.

Tettamanti, M., Veeraraghavan, P. and Pereira S. The impact of facts from the rehabilitation of laboratory rabbits on reliability and evaluation of experimental data. from http://wwww.icareworldwide.org/images/poster_4_rabbits.pdf.

Tettamanti, M., Veeraraghavan P. and Pereira S. The success of the Concept of the 4th R: A new era in laboratory animal care , from http://wwww.icare-worldwide.org/images/poster_3_rehabanimals.pdf.

Van Loo, P.L.P., Van Zutphen, L.F.M. and Baumans, V. (2003) Male management: coping with aggression problems in male laboratory mice. Laboratory Animals 37(4): 300-313.

Wald, C. and Wu C. (2010) Of Mice and Women: The Bias in Animal Models. Science 327(5973): 15711572.

Weekley, L. B., Guittin, P. and Chamberland, G. (2002) The international symposium on regulatory testing and animal welfare: recommendations on best scientific practices for safety evaluation using nonrodent species. ILAR Journal 43 Suppl: S118-122.

Weele, C. (2014) In Vitro Meat. Encyclopedia of Food and Agricultural Ethics. P. B. Thompson and D. M. Kaplan. Dordrecht, Springer Netherlands: 1219-1225.

Wolfensohn, S. (2010) Euthanasia and Other Fates for Laboratory Animals. The UFAW Handbook on the Care and Management of Laboratory and Other Research Animals. R. Hubrecht and J. Kirkwood, Wiley-Blackwell: 219-226.

Yeates, J. (2010) Death is a Welfare Issue. Journal of Agricultural and Environmental Ethics 23(3): 229241. 